\title{
EVALUASI PRODUKTIVITAS PENGOLAHAN HASIL PANEN MENGGUNAKAN MESIN THRESHER DENGAN COMBINE HARVERTER
}

\author{
${ }^{1)}$ Ahmad Hanafie, ${ }^{2)}$ A. Haslindah, ${ }^{3)}$ Saripuddin M, ${ }^{4)}$ Awaluddin Yunus \\ ${ }^{1,2}$ Dosen Program Studi Teknik Industri Fakultas Teknik Universitas Islam Makassar \\ ${ }^{3)}$ Dosen Program Studi Teknik Mesin Fakultas Teknik Universitas Islam Makassar \\ ${ }^{4)}$ Dosen Program Studi Agribisnis Fakultas Pertanian Universitas Islam Makassar \\ Jl.Perintis Kemerdekaan KM 9 NO 29 Kampus UIM, Tlpn 0411-588-167 \\ Email : ahmadhanafie.dty@uim-makassar.ac.id,andihaslindah.dty@uim-makassar.ac.id, \\ saripuddinmuddin.dty@uim-makassar.ac.id,awaluddinyunus.dty@uim-makassar.ac.id
}

\begin{abstract}
ABSTRAK
Perkembangan alat pertanian semakin banyak dan perlu selalu dilakukan perbaikanperbaikan sistem baik terhadap alat yang digunakan maupun penggunaan sumber daya manusia tujuannya adalah pengolahan hasil panen dapat mengefesiensi biaya dan produktivitas. Metode penelitian Jenis dan sumber data yang diperlukan dalam penelitian ini data primer dan skunder, Observasi mengadakan penelitian atau pengamatan pada obyek penelitian berupa pengamatan langsung terhadap pengguna mesin perontok padi thresher dan mesin perontok padi (combine harverter). Hasil penelitian menunjukkan evaluasi mesin thresher dan mesin combine harverter proses kegiatan yang sangat panjang dan tidak efesien dan membutuhkan jumlah tenaga kerja yang banyak sehinga produktivitas rendah. Serta banyaknya kegiatan-kegiatan atau proses yang harus dilalui baru sampai tahap pengemasan dan waktu yang dibutuhkan sebesar 36,404 menit/ $100 \mathrm{~kg}$ butiran padi yang dihasilkan.
\end{abstract}

Kata Kunci: Evaluasi, Thresher, Combine Harverter

\section{PENDAHULUAN}

\subsection{Latar Belakang}

Indonesia adalah salah satu penghasil beras terbesar di dunia dan Kaputen Pinrang sebagai lumbung padi di Indonesia. Perkembangan alat pertanian semakin banyak dan perlu selalu dilakukan perbaikanperbaikan sistem baik terhadap alat yang digunakan maupun penggunaan sumber daya manusia tujuannya adalah pengolahan hasil panen dapat mengefesiensi biaya dan produktivitas. Pada penelitian sebelumnya telah dilakukan penelitian tentang mesin thresher, mesin thresher adalah mesin perontok padi menggunakan mesin. Dalam melakukan proses pengerjaan dilakukan beberapa pekerja secara bergantian dengan posisi kerja berdiri, serta terdiri dari beberapa rangkaian kegiatan yang dilakukan yaitu tenaga kerja bagian pemotongan, pengumpul, operator mesin, pengemasan. Tenaga kerja yang digunakan berkisar antara $15-20$ orang tenaga kerja dengan luas sawah yang mampu dalam hari yaitu satu hektar. Kemudian alat mesin perontok padi diganti dengan combine harverter mesin ini sifatnya statis yang artinya mesin bergerak kelahan pertanian untuk merontokkan padi. Tenaga kerja dibutuhkan hanya 3-5 orang tenaga kerja, serta luas area perhari bisa mencapai 3-4 hektar perhari. Dari kedua mesin thresher combine harverter selama ini mampu membantu petani dalam pengolahan hasil panen, masih perlu di evaluasi dari tingkat efesiensi dan produktivitasnya. Hasil combine harverter masih perlu diproses sampai hasil rontokan menjadi bersih, yaitu hasil combine harverter dikeluarkan dari bak besar, lalu dikumpulkan disuatu tempat, kemudian diangkut secara 
manual ke mesin threseher untuk di perontokan kedua untuk memisahkan batang dan daunya, setelah itu ditapis kemudian dimasukkan kedalam karung atau bagian pengemasan.

\section{METODOLOGI PENELITIAN}

\subsection{Lokasi Penelitian}

Penelitian dilakukan di Kabupaten Pinrang, Kabupaten Pinrang adalah salah satu penghasil mesin perontok padi thresher dan combine harverter juga sebagai pengguna paling banyak di Sulawesi Selatan bahkan di Indonesia.

\subsection{Jenis dan Sumber Data}

Jenis dan sumber data yang diperlukan dalam penelitian ini data primer yaitu data yang diperoleh yaitu pertama, Observasi mengadakan penelitian atau pengamatan pada obyek penelitian berupa pengamatan langsung terhadap pengguna mesin perontok padi thresher dan mesin perontok padi (combine harverter). Data skunder yaitu data yang diperoleh dari jurnal-jurnal nasional dan internasional, seminar-seminar nasional maupun internasional serta buku - buku referensi dari berbagai sumber bacaan yang berkaitan dengan penelitian.

\section{ANALISA DAN PEMBAHASAN}

Berdasarkan hasil penelitian waktu produksi dibutuhkan untuk merontokkan padi dengan menggunakan mesin combine harverter yaitu waktu baku atau waktu standar yang dibutuhkan dalam menyelesaikan pekerjaan dibutuhkan sebesar 1,72 menit dengan kapasitas $50 \mathrm{~kg}$. Setelah selesai merontokkan dibongkar pada tempat yang ditentukan waktu dibutuhkan 3,5 menit, seperti terlihat pada Gambar 1 dan Gambar 2 dibawah ini.

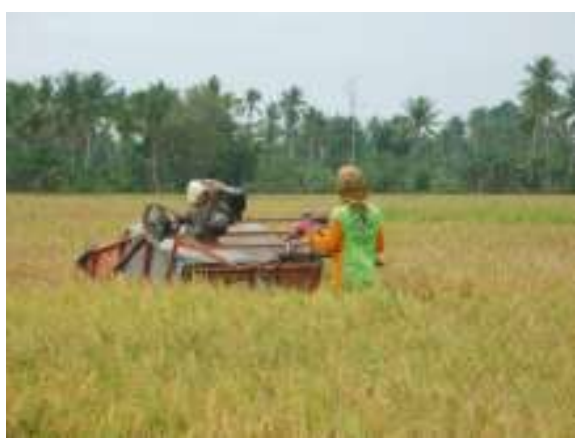

Gambar 1. Proses perontokan dengan mesin combine harverter

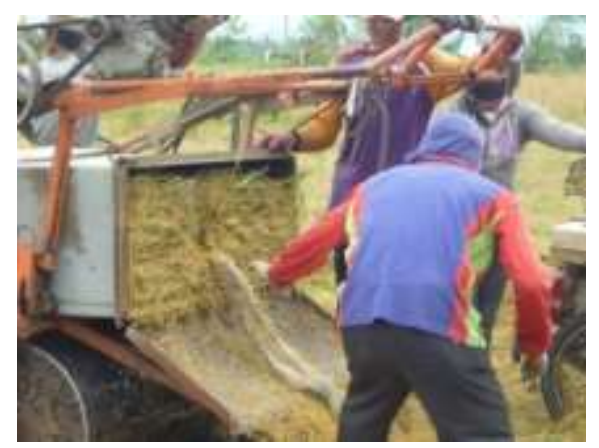

Gambar 2. Proses pembongkaran

Kemudian butiran padi yang masih tercampur dengan batang padi dan daun-daun diproses ke bagian thresher, sebelum ke thresher ada beberapa tahap pertama seorang mengumpulkan butiran padi ke dalam ember berkapasitas $10 \mathrm{~kg}$ dengan menggunakan cangkul waktu yang dibutuhkan kurang lebih 1 menit, lalu diangkut ke mesin thresher dengan tenaga kerja yang berbeda dengan waktu berkisar 30 detik. Setelah barulah dilakukan pembersihan dengan menggunakan mesin perontok thresher waktu yang dibutuhkan berdasarkan hasil penelitian sebelumnya Hasil pengolahan dari data waktu operasi adalah waktu standar yang dapat digunakan sebagai dasar perhitungan produktivitas kerja operator. Waktu standar untuk menyelesaikan 1 kwintal gabah (100 kg) adalah 16.964 menit. Peroses pengerjaan dengan menggunakan mesin thresher seperti terlihat pada Gambar 3 dan Gambar 4 . 


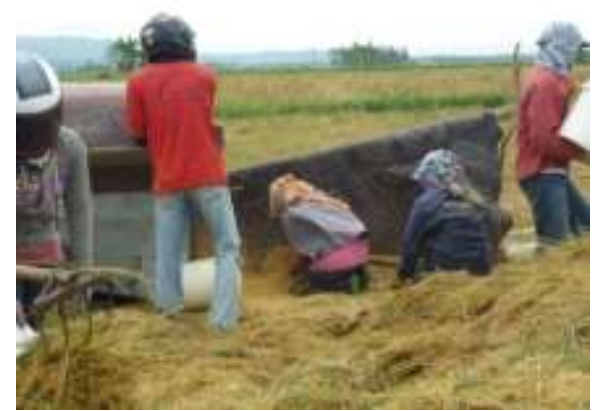

Gambar 3. Proses Perontokan dengan mesin thresher

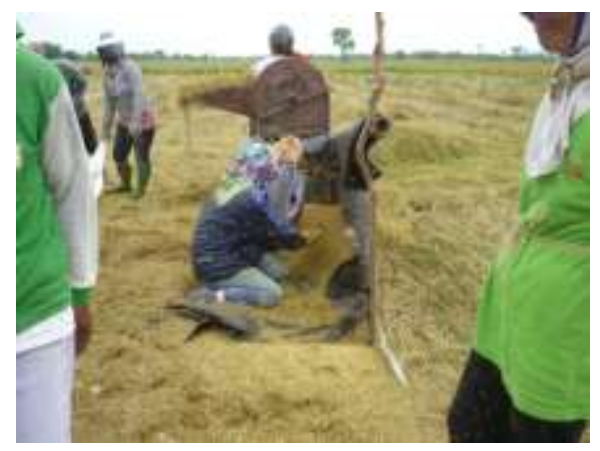

Gambar 4. Proses Pengumpulan hasil rontokan mesin perontok thresher

Butiran padi yang telah dirontokkan dengan menggunakan mesin perontok thresher dikumpulkan lagi oleh salah satu pekerja, butiran padi di kumpulkan dengan menggunakan ember berkapasitas $10 \mathrm{~kg}$ di bawah ke bagian karung waktu dibutuhkan sekitar 1 menit, terakhir setelah penuh diikat dengan waktu 2 menit dengan tenaga kerja berbeda. Seperti Gambar 5 dan Gambar 6.

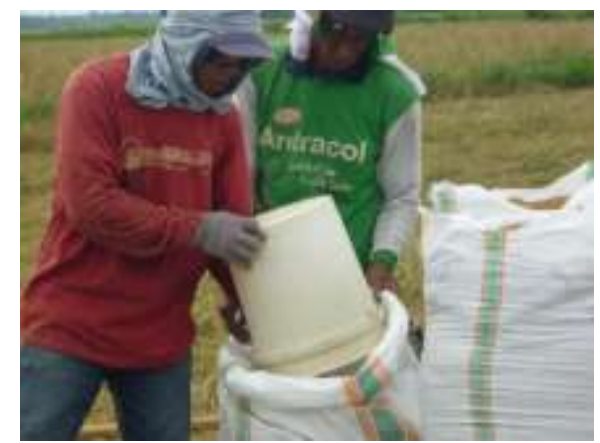

Gambar 5. Proses pengisian pada pengemasan

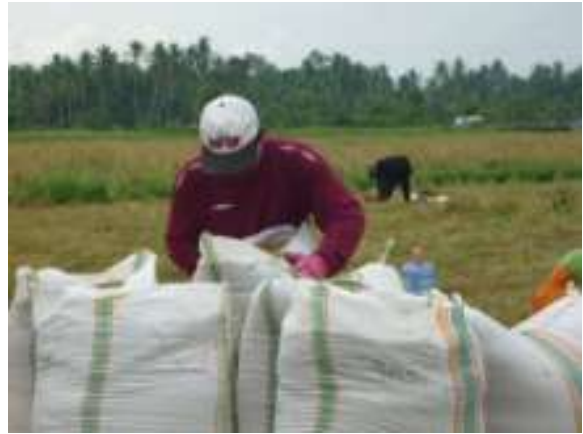

Gambar 6. Proses Pengemasan

Berdasarkan hasil penelitian diatas maka uraian kegiatan proses awal sampai akhir kegiatan dapat dilihat pada tabel 1 .

Tabel 1. Waktu Proses Produksi

\begin{tabular}{|c|c|c|c|}
\hline No. & Uraian & $\begin{array}{l}\text { Uraian } \\
\text { Waktu } \\
\text { Baku per } \\
\text { kegiatan }\end{array}$ & $\begin{array}{l}\text { Waktu yang } \\
\text { dibutuhkan } \\
\text { per } 100 \mathrm{~kg} \\
\text { (menit) }\end{array}$ \\
\hline 1 & $\begin{array}{l}\text { Perontokan dengan } \\
\text { menggunakan mesin } \\
\text { combine harverter }\end{array}$ & $\begin{array}{l}1,72 \\
\text { menit / } 50 \\
\mathrm{~kg}\end{array}$ & 3,44 \\
\hline 2 & $\begin{array}{l}\text { Pengeluaran hasil } \\
\text { rontokan dari bak } \\
\text { besar }\end{array}$ & $\begin{array}{l}2 \text { menit / } \\
50 \mathrm{~kg}\end{array}$ & 4,00 \\
\hline 3 & $\begin{array}{l}\text { Proses pengumpulan } \\
\text { butiran padi ke } \\
\text { dalam ember dengan } \\
\text { menggunakan } \\
\text { cangkul }\end{array}$ & $\begin{array}{l}1 \text { menit / } \\
10 \mathrm{~kg}\end{array}$ & 10,00 \\
\hline 4 & $\begin{array}{l}\text { Penganngkutan dari } \\
\text { tempat } \\
\text { pengumpulan } \\
\text { tempat } \\
\text { thresher }\end{array}$ & $\begin{array}{lr}0, & 5 \\
\text { menit/ } & 10 \\
\mathrm{~kg}\end{array}$ & 5,00 \\
\hline 5 & $\begin{array}{l}\text { Proses perontokan } \\
\text { dengan } \\
\text { menggunakan mesin } \\
\text { thresher }\end{array}$ & $\begin{array}{l}16,964 \\
\text { menit/ } \\
100 \mathrm{~kg}\end{array}$ & 16,964 \\
\hline 6 & $\begin{array}{l}\text { Pengumpulan hasil } \\
\text { mesin thresher dan } \\
\text { dibawah ke bagian } \\
\text { karung }\end{array}$ & $\begin{array}{l}1 \text { menit / } \\
10 \mathrm{~kg}\end{array}$ & 10,00 \\
\hline 7 & $\begin{array}{l}\text { Proses pengisian } \\
\text { pada karung dan } \\
\text { pengikatan }\end{array}$ & $\begin{array}{l}2 \text { menit / } \\
100 \mathrm{~kg}\end{array}$ & 2,00 \\
\hline
\end{tabular}




\section{PEMBAHASAN}

Hasil penelitian menunjukan perontokkan dengnan menggunakan mesin combine harveter setiap siklus kegiatan membutuhkan waktu sebesar 1,72 menit dengan kapasitas bak besar $50 \mathrm{~kg}$ dan dikonversi ke waktu kegiatan per $100 \mathrm{~kg}$ diperoleh waktu untuk penyelesaain perontokan mesin combine harverter 3,44 menit, dari hasil mesin combine harverter butiran padi yang ada dibak besar dengan kapasitas $50 \quad \mathrm{~kg}$ dikeluarkan oleh seorang tenaga kerja yang khusus menangani waktu yang dibutuhkan persiklus kegiatan yaitu 2 menit dan dikonversi ke per $100 \mathrm{~kg}$ maka waktu yang dibutuhkan sebesar 4 menit. Begitu pula pada kegiatan selanjutanya proses pengumpulan butiran padi kedalam ember dengam neggunakan cangkul waktu per ember 1 menit/ $10 \mathrm{~kg}$ bila dikonversi ke $100 \mathrm{~kg}$ maka waktu dibutuhkan sebsar 10 menit, pengangkutan dari tempat pemgpunan ke tempat mesin thresher waktu yang dibutuhkan sebesar 5 menit. Kemudian proses perontokan dengan menggunakan mesin thresher waktu yang dibutuhkan 16,964 menit. Setelah hasil mesin thresher maka dikumpulkan lagi untuk dimasukkan kedalam karung waktu yang dibutuhkan sebesar 10 menit dan terakhir proses pengisian dan penjahitan karung dengan kapasitas $100 \mathrm{~kg}$ waktu yang dibutuhkan 2 menit/karung. Panjangnya dari proses awal sampai akhir waktu yang dibutuhkan 36, 404 menit dan melibatkan 7 tenga kerja. Berdasarkan hasil evaluasi mesin thresher dan mesin combine harverter proses kegiatan yang sangat panjang dan tidak efesien dan membutuhkan jumlah tenaga kerja yang banyak sehingan produktivitas rendah.

\section{PENUTUP}

\subsection{Kesimpulan}

Hasil penelitian menunjukkan evaluasi mesin thresher dan mesin combine harverter proses kegiatan yang sangat panjang dan tidak efesien dan membutuhkan jumlah tenaga kerja yang banyak sehingga produktivitas rendah. Serta banyaknya kegiatan-kegiatan atau proses yang harus dilalui baru sampai tahap finishing dan waktu yang dibutuhkan sebesar 36,404 menit/ $100 \mathrm{~kg}$ butiran padi yang dihasilkan.

\section{UCAPAN TERIMA KASIH}

Ucapan terima kasih kepada Menristek Dikti atas pembiayaan yang diberikan kepada peneliti melalui penelitian Program Masterplan Percepatan dan Perluasan Pembangunan Ekonomi Indonesia (MP3EI) pendanaan tahun anggaran 2017

\section{DAFTAR PUSTAKA}

Ahmad Hanafie (2007), Modifikasi Helm Standar Kendaraan Roda Dua Yang Ergonomis Bagi Penguna Telpon Seluler, Jurnal Iltek, Vol. II, Nomor 4, April 2007, Hal 313-319, Fakultas Teknik Univ. Islam Makassar.

Ahmad Hanafie, Darmulia (2014), Pengembangan Mesin Perontok Padi (Combine Harverter) yang Ergonomis Untuk Meningkatkan Produksi, Prosiding Seminar Nasional Teknologi Industri II Atim 2014, ISSN. 978-60214822-16, Hal. 346-381.

Ahmad Hanafie, A.Haslindah, Muh. Fadhli (2015), Pengembangan Mesin Perontok Padi (Combine Harverter) yang Ergonomis Untuk Meningkatkan Produksi, Majalah Teknik Industri, Vol. 22/No.1/Juni 2015, ISSN. 1410-7015, Hal. 67-72.

Ahmad Hanafie, A.Haslindah, Muh. Fadhli (2015), Pengembangan Mesin Perontok Padi (Combine Harverter) yang Ergonomis Untuk Meningkatkan Produksi, Prosiding Seminar Nasional Tahunan Teknik Mesin Indonesia-XIV, Banjarmasing, 7-8 Oktober 2015.

Ahmad Hanafie, Hammada Abbas, Lawalenna, Sumarni Hami (2016), Study Of Vehicles Utilities And LoadUnloading Facilities Of City Public Transport Based On Ergonomics Assessment, International Journal of 
Advances in Scientific Research and Engineering (ijasre.net) Volume-1, Issue3, December - 2015.

Astika (2007), Ergonomi Pertumbuhan Dan Peranannya Dalam Pembangunan, http://www.baliheag.org.

Eko Nurmianto (2007), Ergonomi, konsep dasar \& aplikasinya, Penerbit Guna Widya, Jakarta.

Iftikar Z. Sutalaksana; Ruhana A; John H. T (2006), Analisa dan Perancangan Sistem Kerja. Jurusan TI ITB.

Muh. Yani Syafei Dr,H.,ST.,MT, (2007), Aplikasi Konsep Ergonomi Dalam Pengembangan Design Produk Akan Memberikan Nilai Jual Produk yang Tinggi dan dan Keunggulan Bersaing. Seminar Nasional Ergonomics in product Development.

Noor Fitrihana, (2007), Memperbaiki Kondisi Kerja di Industri Garmen, Ergonomi Kerja, B4D3 Consultants, hal 1- 12.

Karl T. Ulrich, Steven D. Eppinger (2001), Perancangan dan Pengembangan Produk, Mc Graw Hill.

Roche; Davila, USA (1972), Dalam bukunya Wignjosoebroto, Sritomo Sritomo (2000), Ergonomi, Studi Gerak \& waktu. Penerbit Guna widya, Jakarta.

Sritomo Wignjosoebroto, (2008), Ergonomi, Studi Gerak \& waktu. Penerbit Guna widya, Jakarta.

Sritomo Wignjosoebroto, Srigunani, Ahmad Hanafie. (2003), Modifikasi mesin perontok Padi yang Ergonomis. PEI, Yogyakarta.

Sudjana (1989), Metoda Statistika, penerbit Tarsito, Bandung.

Usulan Perbaikan Sistem Kerja yang Lebih Ergonomis pada Stasiun Kerja Perakitan dan Pemolesan di PT. YPTI, Jun 15 th, 2007 by admin.

Ergonomi

Industri, http://adibuana.com/web. Universitas PGRI Adibuana Surabaya (2008). 